J U R N A L M E T A M O R F O S A

Journal of Biological Sciences

ISSN: 2302-5697

http://ojs.unud.ac.id/index.php/metamorfosa

\title{
Konservasi Air Sebagai Program Green Hotel \\ Pada Hotel Melati Di Kawasan Pariwisata Sanur; Bali
}

\author{
Water Conservation As Green Hotel Program \\ For Jasmine Hotel In Sanur Tourist Resort, Bali
}

\author{
Stephanie Felitania Lestari ${ }^{1}$, A.A.G. Raka Dalem ${ }^{2,3}$, I K Sundra ${ }^{2}$ \\ ${ }^{1) 2)}$ Program Studi Biologi, FMIPA, Universitas Udayana, Bali \\ ${ }^{3)}$ Kelompok Studi Ekowisata dan Pembangunan Berkelanjutan \\ *E-mail: aniefelitania@gmail.com
}

\section{INTISARI}

Sanur merupakan satu dari Sustainable Toursim Observatory (STO) yang terdapat di Indonesia. Sanur juga merupakan salah satu kawasan pariwisata tertua di Bali, dan juga satu-satunya kawasan pariwisata di Kota Denpasar, Kawasan Pariwisata Sanur (KPS) tidak dapat terhindar dari berbagai permasalahan. Hotel melati yang terdapat pada kawasan ini juga menghadapi permasalahan, salah satunya adalah permasalahan air. Menanggapi hal tersebut, Kementrian Pariwisata Republik Indonesia menghimbau seluruh hotel untuk mengembangkan pariwisata yang ramah lingkungan melalui penerapan prinsip-prinsip Green Hotel. Hal tersebut dilakukan agar hotel melakukan berbagai perbaikan untuk mewujudkan pariwisata berkelanjutan. Penelitian ini dilakukan untuk mengetahui kinerja implementasi Green Hotel, khususnya aspek konservasi air pada hotel melati di KPS. Pengambilan data dilakukan pada bulan Agustus hingga Desember 2018 melalui observasi, wawancara, penyebaran kuesioner, studi literatur, dan pemeriksaan dokumen. Data dianalisis secara deskriptif kualitatif dan kuantitatif. Hasil penelitian menunjukan bahwa penerapan konservasi air di KPS hanya dilakukan dengan baik oleh $23,08 \%$ hotel di kawasan tersebut, sementara itu sebanyak $76,92 \%$ belum menerapkannya dengan baik.

Kata kunci: konservasi air, pariwisata berkelanjutan, hotel melati

\begin{abstract}
Sanur is a Sustainable Tourism Observatory (STO) in Indonesia. Sanur is also one of the oldest tourist resort in Bali, and it is the only tourist resort in Denpasar city. Sanur Tourist Resort couldn't avoid various problems. Jasmine hotel in this area must face the same problems, such as fresh water crisis. Responding to this, Indonesian's Tourism Ministry appealed to the entire hotels to develop ecofriendly tourism through implementation of Green Hotel programs. Thus, the hotels should conduct various efforts towards sustainable tourism. This research was conducted in order to find out the performance of jasmine hotels in Sanur Tourist Resort in implementing Green Hotel principles, related especially related to water conservation. Data were collected between August and December 2018 through observation, interviews, distributed questionnaires, literature study and checking documents. The data were qualitatively and quantitatively analysed. The results showed that in Sanur Tourist Resort the implementation of water conservation has been implemented well by $23.08 \%$ of jasmine hotels only but $76.92 \%$ of them have not did it well.
\end{abstract}

Keyword: water conservation, sustainable tourism, jasmine hotel 


\section{PENDAHULUAN}

Pariwisata adalah sektor industri terbesar yang telah menjadi andalan utama Indonesia untuk mendapatkan devisa negara. Laporan tahunan UNWTO menyebutkan bahwa, kedatangan turis internasional pada tahun 2017 adalah 1,323 milyar, dan lebih dari $6 \%$ diantaranya datang ke Indonesia. Sementara itu sejumlah 625.431 wisatawan tercatat mengunjungi Denpasar (WTO, 2018).

Kawasan Pariwisata Sanur adalah satusatunya kawasan pariwisata yang terdapat di Kota Denpasar. Kawasan ini juga merupakan salah satu kawasan pariwisata tertua di Bali, dan merupakan satu dari STO (Sustainable Tourism Observatory) di Indonesia, dan satu dari 21 STO seluruh dunia. STO adalah salah satu program UNWTO-INSTO yang bergerak dalam pariwisata dunia untuk mendukung Millenium Development Goals (MDG) terutama MDG 7 mengenai kelestarian lingkungan (UNWTOINSTO, 2018) maupun sustainable development goals (SDGs).

Menurut Subadra dan Nadra (2006), mass tourism yang terjadi di KPS menyebabkan peningkatan secara drastis jumlah pelayanan khususnya penginapan dan juga kebutuhan sumber daya alam, termasuk air. Bila hal ini tidak dikendalikan, maka permasalahan lingkungan seperti krisis air bersih akan terjadi. Menurut JICA, Japan International Coorperation Agency (2006), kebutuhan air domestik atau kebutuhan total air pada tahun 2005 untuk keseluruhan Kota Denpasar adalah 1.180 liter/detik. Kebutuhan air non-domestik untuk pariwisata di Provinsi Bali diperkirakan $3,3 \mathrm{~m}^{3}$ atau $3.300 \mathrm{~L} / \mathrm{kamar} /$ hari untuk hotel bintang dan $1,5 \mathrm{~m}^{3}$ atau $1.500 \mathrm{~L} / \mathrm{kamar} /$ hari untuk hotel non-bintang. Kapasitas PDAM Denpasar tercatat pada tahun 2005 adalah hanya 1.115 liter/detik. Berdasarkan hasil prediksi, bila tidak dilakukan manajemen air bersih dan pengelolaan sumber air baru, maka pada tahun 2025 di Kota Denpasar akan terjadi kecenderungan krisis air sejumlah 1.690 liter/detik (JICA, 2006).

Menurut data Direktori 2018 dari Dinas Pariwisata Provinsi Bali, akomodasi di Bali dengan jumlah kamar tertinggi adalah hotel melati (39.175 kamar), kemudian hotel bintang (33.636 kamar), serta pondok wisata (11.603 kamar). Akomodasi wisata di Bali dominan tersebar di Kabupaten Badung, Kota Denpasar dan Kabupaten Gianyar.

Respon untuk menghadapi permasalah krisis air di Indonesia, termasuk Bali, oleh Kementrian Pariwisata Republik Indonesia adalah menghimbau dilakukannya penerapan program Green Hotel pada seluruh hotel, termasuk hotel melati di KPS ini. Green Hotel ini berlaku sebagai pedoman untuk memandu, mengajar dan menyertifikati industri perhotelan dan pariwisata agar terjadi peningkatan kualitas lingkungan dan alam secara berkelanjutan. Selain untuk menghadapi permasalah lingkungan, pedoman ini dapat membantu hotel untuk bersaing dalam industri pariwisata seASEAN yang juga mulai menerapkan pariwisata berwawasan lingkungan. Hal ini salah satunya juga untuk menjawab tuntutan wisatawan saat ini yang juga mulai selektif untuk memilih akomodasi/penginapan yang ramah lingkungan (Kementrian Pariwisata Republik Indonesia, 2016).

Berdasarkan hal tersebut, maka tujuan penelitian ini adalah untuk mengetahui kinerja implementasi aspek konservasi air dari program Green Hotel pada hotel-hotel melati di Kawasan Pariwisata Sanur, Bali. Penelitian ini diharapkan dapat menjadi bahan evaluasi bagi pihak berkepentingan dan memberikan rekomendasi solusi untuk menghadapi permasalahan lingkungan.

\section{BAHAN DAN METODE}

Penelitian mengenai kinerja konservasi air Green Hotel pada hotel melati ini dilakukan di Kawasan Pariwisata Sanur. Penelitian dilakukan dari bulan Agustus 2018 hingga Desember 2018 dengan teknik pengambilan sampel stratified random sampling (sampel acak bertingkat) dengan jenis proportionate stratified sampling (sampel bertingkat proposional).

Sampel pada penelitian ini diambil sebesar $16 \%$, yaitu berjumlah 13 hotel melati yang terletak di Kawasan Pariwisata Sanur (KPS). Pengumpulan data dilakukan melalui observasi, studi literatur, pemeriksaan 
dokumen, wawancara dan penyebaran kuisioner dengan jenis data yang diperoleh adalah data kualitatif dan kuantitatif yang didapat dari sumber primer maupun sekunder. Data dianalisis secara deskriptif kualitatif dan kuantitatif.

\section{HASIL}

Hasil kinerja aspek konservasi air dari program Green Hotel di hotel-hotel melati pada KPS dapat dilihat pada Gambar 1.

\section{Presentase Hotel \\ dalam Penerapan Aspek Konservasi Air}

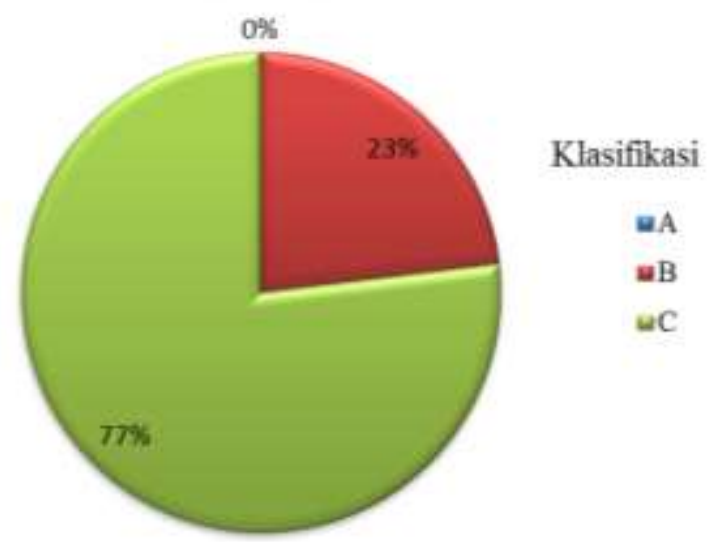

Gambar 1. Penerapan kriteria konservasi air Program Green Hotel pada hotel melati di KPS (A) sangat baik, (B) cukup baik, (C) kurang baik.

Penelitian menunjukan bahwa hanya terdapat $23.08 \%$ hotel melati di KPS yang telah menerapkan dengan cukup baik kriteria Green Hotel untuk mengkonservasi air, sementara itu sejumlah $76.92 \%$ belum menerapkan Green Hotel dengan baik. Hasil penilaian kinerja konservasi air dapat dilihat pada Tabel 1.

Kinerja konservasi air pada Program Green Hotel terdiri atas enam buah aspek penilaian: kebijakan manajemen air, pemasangan sub-meter air, kontrol pengawasan air, kualitas air, pendaurulangan sumber air dan penyediaan air minum (Kementrian Pariwisata Republik Indonesia, 2016).

Terdapat tiga buah poin dari kriteria Green Hotel untuk konservasi air yang telah dilakukan oleh lebih dari $80 \%$ hotel melati di KPS. Ketiga poin penilaian tersebut adalah adanya tim konservasi air yang memastikan pemakaian air yang efektif dan efisien $(92,31 \%)$, pemeriksaan pompa air $(84,62 \%)$ dan juga pemeriksaan dari kebocoran $(92,31 \%)$.

Sejumlah tujuh poin kriteria konservasi air pada Green Hotel baru dilakukan oleh 50 $79 \%$ hotel melati di KPS. Ketujuh poin tersebut adalah konsumsi air yang berupa tagihan air dari pemerintah baik PDAM ataupun ABT $(53,85 \%)$, adanya edukasi bagi staff $(53,85 \%)$, kepemilikan sub-meter air $(53,85 \%)$, kepemilikan $(53,85 \%)$ dan pemeriksaan $(61,54 \%)$ water fixture yang dapat menekan konsumsi air, kepemilikan laporan manajemen pemeliharaan kolam renang secara berkala $(76,92 \%)$ dan program meminimalisasi penggunaan ABT atau air bawah tanah $(69,23 \%)$.

Sejumlah lima poin penilaian kriteria konservasi air pada Green Hotel baru dilakukan oleh sekitar 30 - 39\% hotel melati di KPS, sedangkan sejumlah tujuh poin sama sekali belum dilakukan oleh hotel melati di KPS dan sejumlah dua poin penilaian tidak mungkin dilakukan. Lima poin yang baru dilakukan oleh $30-39 \%$ hotel adalah adanya edukasi atau kampanye efisiensi air bagi wisatawan $(30,77 \%)$; pemeriksaan sub-meter $(30,77 \%)$; kepemilikan hasil laboratorium air besih $(38,46 \%)$ dan air kolam renang $(38,46 \%)$; serta pengadaan air minum non-kemasan untuk mengurangi jejak karbon $(30,77 \%)$.

Berikut pada Tabel 2 dapat dilihat kinerja poin-poin terkait sumber daya air pada program Green Hotel yang bukan merupakan poin aspek konservasi air. Poin-poin ini dapat ditemukan pada aspek manajemen lingkungan sekitar. 
Tabel 1. Penerapan tiap kriteria konservasi air Program Green Hotel pada hotel melati di KPS

\begin{tabular}{|c|c|}
\hline Kriteria Penilaian & $\begin{array}{c}\% \\
\text { Hotel } \\
\end{array}$ \\
\hline \multicolumn{2}{|l|}{ (KEBIJAKAN MANAJEMEN AIR) } \\
\hline Tim konservasi air & 92,31 \\
\hline konsumsi air & 53,85 \\
\hline $\begin{array}{l}\text { evaluasi sebelum dan sesudah Green } \\
\text { Hotel }\end{array}$ & N/A \\
\hline kampanye staff & 53,85 \\
\hline kampanye tamu & 30,77 \\
\hline $\begin{array}{l}\text { (PEMASANGAN SUB-METER } \\
\text { AIR) }\end{array}$ & \\
\hline $\begin{array}{l}\text { punya sub meter } \\
\text { (KONTROL PENGAWASAN AIR) }\end{array}$ & 53,85 \\
\hline $\begin{array}{l}\text { alat bantu efisiensi air bersih } \\
\text { (sensor, timer) }\end{array}$ & 0 \\
\hline water fixture & 53,85 \\
\hline pemeriksaan sub meter & 30,77 \\
\hline pemeriksaan water fixture & 61,54 \\
\hline pemeriksaan pompa air & 84,62 \\
\hline $\begin{array}{l}\text { pemeriksaan dari kebocoran } \\
\text { (KUALITAS AIR) }\end{array}$ & 92,31 \\
\hline hasil laboratorium air bersih & 38,46 \\
\hline hasil laboratorium kolam berenang & 38,46 \\
\hline $\begin{array}{l}\text { laporan manajemen kolam renang } \\
\text { (PENDAUR-ULANGAN SUMBER } \\
\text { AIR) }\end{array}$ & 76,92 \\
\hline air daur ulang dari laundry & 0 \\
\hline air daur ulang dari $\mathrm{F} \& \mathrm{~B}$ & 0 \\
\hline air daur ulang dari peribadahan & N/A ${ }^{1)}$ \\
\hline $\begin{array}{l}\text { air daur ulang untuk flush toilet atau } \\
\text { penyiraman }\end{array}$ & 0 \\
\hline air daur ulang untuk hal lainnya & 0 \\
\hline penggunaan air hujan & 0 \\
\hline $\begin{array}{l}\text { penggunaan air selain PDAM, ABT } \\
\text { dan air hujan }\end{array}$ & 0 \\
\hline upaya minimalisasi $\mathrm{ABT}$ & 69,23 \\
\hline (PENYEDIAAN AIR MINUM) & \\
\hline air minum non kemasan & 30,77 \\
\hline
\end{tabular}

Keterangan: ${ }^{1)} \mathrm{N} / \mathrm{A}=$ not applicable atau tidak mungkin dilakukan 
Tabel 2. Penerapan Kriteria Green Hotel terkait sumber daya air pada Hotel Melati di KPS

\begin{tabular}{|c|c|}
\hline Kriteria Penilaian & $\begin{array}{l}\% \\
\text { Hotel }\end{array}$ \\
\hline (ORGANISASI) & \\
\hline penjaga prinsip sustainability & 53,85 \\
\hline gerakan green & 76,92 \\
\hline $\begin{array}{l}\text { (MANAJEMEN PENGOLAHAN } \\
\text { LIMBAH) }\end{array}$ & \\
\hline pemanfaatan kembali limbah padat & 15,39 \\
\hline pengolahan limbah B3 & 7,69 \\
\hline pengolahan limbah padat & 15,39 \\
\hline pengolahan limbah medis & N/A ${ }^{1)}$ \\
\hline $\begin{array}{l}\text { penanganan limbah padat organik } \\
\text { dari restoran }\end{array}$ & 30,77 \\
\hline $\begin{array}{l}\text { pemisahan sampah organik dan } \\
\text { anorganik }\end{array}$ & 53,85 \\
\hline mengurangi limbah padat & 15,39 \\
\hline IPAL dari resto dll (bukan WC) & 7,69 \\
\hline IPAL dari WC & 7,69 \\
\hline
\end{tabular}

\section{PEMBAHASAN}

Menurut Anggita dkk (2016), penelitian mengenai lingkungan dalam hotel sulit dilakukan, karena tingkat kehijauan merupakan pembahasan yang sensitif bagi pemilik bangunan komersial seperti hotel. Robinot dan Giannelloni (2010) menambahkan, bahwa atribut pengelolaan lingkungan bahkan sebaiknya tidak diinformasikan secara langsung karena akan berdampak pada resiko penilaian yang kurang layak dari tamu hotel. Meskipun demikian, pengelolaan lingkungan penting untuk dilakukan mengingat manfaat yang diberikan nantinya dapat mengurangi biaya operasi bahkan mempengaruhi pandangan para pemegang saham, konsumen hotel, dan operator parawisata (Pramono, 2016). Hal tersebut yang mungkin menyebabkan pengelola hotel di 13 hotel yang ditargetkan menjadi objek penelitian mengijinkan pengambilan data penelitian pada hotel-hotel tersebut.

\section{Poin - Poin dalam Kriteria Green Hotel yang Diterapkan oleh Sebagian Besar Hotel (Lebih dari 80\% Hotel)}

Sebanyak 92,31\% hotel melati di KPS sudah memiliki tim konservasi air yang bertanggung jawab untuk memastikan penggunaan air dijalankan secara efektif dan efisien, namun jumlah staff yang sedikit pada hotel melati menyebabkan tim ini hanya terdiri dari satu hingga tiga orang saja. Kehadiran tim konservasi air memegang pengaruh besar terhadap tingkat konsumsi air karena tim ini berperan sebagai pemantau, pembuat strategi, dan juga pelaku manajemen konservasi air.

Pemeriksaan pompa air $(84,62 \%)$ dan pemeriksaan dari kebocoran $(92,31)$ merupakan dua poin dalam kriteria Green Hotel yang sudah dilakukan oleh sebagian besar hotel melati. Hal ini menunjukan pentingnya terlaksana kedua poin tersebut untuk menjaga tingkat konservasi air. Tim konservasi harus menjaga kualitas pompa air agar air bisa disalurkan dengan baik ke seluruh kamar hotel. Kebocoran pada pipa maupun alat sanitasi air tentunya juga perlu dihindari karena kebocoran merupakan faktor utama terjadinya peningkataan konsumsi air, seperti yang terjadi di banyak gedung di Jakarta yang mengalami pemborosan hingga 50\% karena kebocoran (Pemerintah Provinsi DKI Jakarta, 2012).

\section{Poin-Poin dalam Kriteria Green Hotel yang Diterapkan oleh Sekitar 50 - 79\% Hotel}

Pendataan konsumsi air yang dapat diperlihatkan oleh pengelola hotel melati di KPS umumnya berupa tagihan pembayaran air PDAM dan ABT. Seperti yang telah dijelaskan, operasional hotel selalu bertujuan bisnis yaitu untuk menekan biaya operasional yang ditandai dengan menurunnya tagihan air PDAM dan ABT. Tim konservasi 53,85\% sudah memberikan edukasi bagi staff dan pada $76,92 \%$ hotel telah melakukan pemeliharaan kolam berenang secara berkala dengan baik. Pengecekan $\mathrm{pH}$ dan kadar klorin pun dilakukan setiap pagi dengan test kit.

Program minimalisasi konsumsi ABT memang penting dilakukan, namun baru $69,23 \%$ hotel melati di KPS yang 
melakukannya. Menurut Pemerintah Provinsi DKI Jakarta (2012), pengambilan air tanah yang lebih besar dibandingkan dengan kemampuan tanah untuk mengisi kembali cadangan air tanah dari resapan air permukaan, menyebabkan turunnya cadangan air tanah dan mempercepat penurunan muka tanah. Ode (2011) menambahkan bahwa pemanfaatan air bawah tanah yang berlebih di daerah pantai menyebabkan masuknya air laut ke bawah permukaan tanah atau yang disebut dengan intrusi air laut. Menurut Suyanto (2002) dalam Ode (2011), kawasan Sanur dan sekitarnya terancam intrusi air laut hingga $1,2 \mathrm{Km}$ dari lidah ombak atau gelombang air laut yang sampai di daratan.

Water fixture atau perlengkapan air juga sangat berperan penting dalam efisiensi air, sehingga baik penerapan kepemilikan perlengkapan hemat air $(53,85 \%)$ maupun pemeliharaan water fixture $(61,54 \%)$ perlu ditingkatkan oleh setiap pengelola hotel di daerah KPS. Menurut ASHRAE (2006), potensi penghematan dengan menggunakan perlengkapan sanitair dan keran yang efisien pada hotel bisa mencapai $25 \%$. Penggunaan keran aerator dan dual flush toilet merupakan dua perlengkapan air yang telah di gunakan oleh 53,846\% hotel melati di KPS dengan tujuan untuk menekan konsumsi air pada operasional hotelnya.

Keran umumnya mengalirkan air sebanyak 23 liter/menit, sedangkan pada keran aerator, air yang dialirkan hanya 2 - 8 liter/menit. Menurut Pemerintah Provinsi DKI Jakarta (2012), penghematan sebesar 50\% dari penggunaan keran aerator dapat terjadi karena desain nosel yang menambahkan udara pada air yang terjadi bila tekanan lebih dari 1 bar (100 $\mathrm{KPa}$ ). Hal ini menyebablam efek seolah - olah aliran air memiliki volume yang besar.

Pengefektifan air dengan sistem dual flush toilet juga dapat menghemat air karena memiliki tujuan untuk mengalirkan volume air sesuai kebutuhan. Menurut Yudo (2018), produsen umumnya membuat toilet tipe dual flush dengan perbandingan 3:6 liter (3 liter akan dikeluarkan saat penekanan tombol kecil dan 6 liter air akan dikeluarkan saat penekanan tombol besar), namun untuk menghemat air, ada juga produsen yang memproduksi toilet dengan perbandingan 3:4,5 liter (3 liter air untuk penekanan tombol kecil dan 4,5 liter untuk penekanan tombol besar) dan 2,3:4,8 liter $(2,3$ liter air untuk penekanan tombol kecil dan 4,8 liter untuk penekanan tombol besar). Pemeliharaan toilet dapat dilakukan dengan menggunakan pewarna makanan yang diteteskan pada tangki toilet kemudian didiamkan selama 15 menit dan dilakukan pengecekan pada toilet bowl. Air berwarna yang mengalir pada toilet bowl tanpa penekanan flush mengindikasikan kebocoran tangki dan upaya perbaikan dan perawatan harus segera dilakukan (Pemerintah Provinsi DKI Jakarta, 2012).

\section{Poin-Poin dalam Kriteria Green Hotel yang Kurang Diterapkan (Kurang dari 50\% Hotel)}

Kepemilikan hasil uji kualitas air bersih dan air kolam renang baru dimiliki oleh 38,46\% hotel melati di KPS. Berdasarkan pengakuan dari pengelola hotel, rendahnya penerapan poin kepemilikan hasil uji kualitas air bersih dan air kolam renang terjadi karena tingginya biaya pengujian kualitas air yang harus dikerjakan di laboratorium dan juga uji kualitas air yang harus dilakukan minimal setiap 6 bulan sekali. Komplain dari wisatawan mengenai kualitas air sangat jarang terdengar, sehingga uji kualitas air belum menjadi suatu kepentingan yang harus diutamakan oleh pengelola hotel. Kesadaran pengelola untuk menguji kualitas air secara berkala harus ditingkatkan.

Hanya sebanyak 30,769\% hotel melati di KPS yang menerapkan kampanye efisiensi air bagi wisatawannya, pemerikasaan sub-meter dan juga penyediaan air minum non-kemasan bagi wisatawan dengan menyediakan dispenser yang ditaruh pada lorong hotel.

Kampanye efisiensi air yang sudah dilakukan oleh $30,769 \%$ hotel ialah untuk mengurangi intensitas pencucian handuk dan juga linen. Kurangnya kampanye efisiensi air terhadap wisatawan ini disebabkan karena sungkannya pengelola hotel untuk mengingatkan tamu. 
Pemeriksaan sub-meter air memang perlu dilakukan secara berkala oleh tim konservasi hotel sebagai kesadaran pengelola hotel terhadap konsumsi air. Sub-meter umumnya ditempatkan pada sumber pasokan air. Penempatan sub-meter pada lokasi konsumsi juga dapat meningkatkan keakuratan pencatatan konsumsi dan identifikasi lokasi kebocoran atau kerusakan peralatan atau infrastruktur sebagai upaya penghematan air (pemerintah provinsi DKI Jakarta, 2012). Umumnya sub-meter air dapat diletakan di bagian laundry, kitchen, kamar tamu dan pipa irigasi.

Ketujuh poin yang sama sekali belum dilakukan adalah penggunaan air daur ulang dari laundry, food and beverage (F\&B) untuk flush atau penyiraman atau peruntukan lainnya. Menurut Pemerintah Provinsi DKI Jakarta (2012), penerapan sistem daur ulang air baik grey water atau black water memerlukan perencanaan, dan perancangan yang kompleks perlu disertai dengan biaya konstuksi, perawatan dan operasional yang tinggi untuk menghindari resiko kontaminasi dan polusi yang terjadi bila salah pengelolaan. Hal inilah yang menyebabkan sulitnya penerapan sistem daur ulang pada hotel-hotel melati di KPS.

Hal yang sama terjadi pada sistem penampungan dan pemprosesan air hujan atau sumber air lainnya selain PDAM dan ABT yang belum tersedia pada hotel-hotel melati di KPS. Pengadaan alat sensor atau timer keran yang belum dilakukan juga perlu diterapkan oleh pengelola hotel melati di KPS karena menurut Pemerintah Provinsi DKI Jakarta (2012), penggunaan keran tekan dan keran sensor elektronik dapat menghemat air hingga 50\% dan $70 \%$.

Poin yang tidak mungkin dilakukan adalah evaluasi sebelum dan sesudah Green Hotel. Hal ini dikarenakan sebesar $100 \%$ hotel melati di KPS yang diteliti baru pertama kali melakukan sistem manajemen dari prinsip Green Hotel. Penggunaan air daur ulang dari kegiatan ibadah juga tidak dilakukan mungkin karena sedikitnya penggunaan air dalam peribadatan masyarakat agama Hindu.

\section{Poin kriteria Green Hotel pada aspek lain yang terkait sumber daya air}

Selain pengolahan air itu sendiri, pengolahan limbah pun harus dilakukan terkait pencemaran air tanah akibat kurang baiknya pengelolaan limbah. Cairan leachate (lindi) hasil dari dekomposisi anaerob limbah padat merupakan bahan utama pencemar. Leachate atau lindi adalah cairan yang mengandung zat padat yang sangat halus yang tersuspensi akibat proses penguraian mikroba dan dapat mengalir ke sungai, air tanah, dan juga tanah. Gas yang dihasilkan juga mengurangi kenyamanan wisatawan maupun masyarakat, seperti pada kasus TPA Suwung yang bahkan mengganggu aktivitas keagamaan di Pura Sakenan Desa Serangan, Denpasar Selatan (Wardi, 2011).

Berdasarkan evaluasi kriteria pada aspek lain dari Program Green Hotel menunjukan bahwa gerakan "green" di lingkungan sekitar hotel yang telah dilakukan oleh $76,92 \%$ hotel melati di KPS tentunya meningkatkan kualitas air di daerah KPS. Program green yang umumnya dilakukan oleh staff hotel melati adalah beach clean up atau kegiatan membersihkan pantai. Tingginya presentase hotel yang menerapkan poin ini dikarenakan adanya himbauan dari banjar-banjar agar hotel melati pada KPS mengirimkan staffnya dalam kegiatan bersih-bersih lingkungan. Selain itu, ajakan karena adanya suatu acara tertentu mungkin juga terjadi, seperti yang terjadi pada tanggal 18 November 2016, pihak hotel bersama dengan siswa sekolah, pegawai SKPD di kota Denpasar dan beberapa pihak lainnya melaksanakan program clean beach di Pantai Mertasari Sanur. Ketua panitia kegiatannya menyatakan bahwa beach clean up ini terkait dengan program Green Hotel, serta untuk meningkatkan sadar lingkungan pada masyarakat (Bali Travel News, 2016).

Pemisahan limbah padat menurut sifat organik dan anorganiknya merupakan manajemen limbah padat yang sudah dilakukan oleh 53,85 \% hotel melati di KPS. Limbah organik merupakan limbah yang mudah membusuk dan dapat menjadi tempat berkembang biak mikroorganisme patogen sehingga pengolahan limbah organik ini lebih 
mudah dilakukan dengan cara pengomposan, sedangkan limbah anorganik membutuhkan cara lain karena sulit didegradasi oleh mikroorganisme. Limbah anorganik yang tidak diolah dapat menyebabkan peningkatan jumlah ion logam di dalam air sehingga air menjadi sadah. Air yang mengandung ion timbal $(\mathrm{Pb})$, arsen (As), dan raksa (Hg) juga bersifat beracun dan berbahaya bagi tubuh manusia. Limbah yang mengandung bahan kimia juga diharapkan dapat dipisahkan; karena limbah seperti sabun, pemberantas hama, zat warna, detergen, zat radioaktif dan lainnya bila disatukan dengan limbah organik dalam pengolahannya akan menghambat kerja mikroorganisme dalam mendegradasi zat-zat organik. Sistem pembuangan limbah yang kurang baik juga akan menyebabkan tercecernya limbah hingga mencemari sungai bahkan menyumbat selokan (Harmayani dan Konsukartha, 2007). Oleh sebab itu, sangat penting dilakukan pemisahan sampah berdasarkan jenisnya agar dapat diolah sesuai jenisnya. Pemisahan limbah padat yang lebih spesifik telah dilakukan oleh 7,69\% hotel melati di KPS yaitu dengan memisahkan limbah organik, anorganik plastik dan kaleng, anorganik kertas dan anorganik lainnya, seperti yang terlihat pada berikut ini.

Sebanyak 15,39\% hotel melati di KPS telah mengupayakan pengurangan (reduce), pemanfaatan kembali (reuse) dan pengolahan (recycle) limbah. Bahkan terdapat hotel yang mengganti (replace) kemasan plastik dengan kemasan berbahan lain, penggantian plastik laundry dengan keranjang ataupun kain, penggantian wadah sampah dengan kain atau kantong plastik dengan jenis biodegradable, dan juga penggantian sedotan plastik dengan sedotan kertas. Kusminah (2018) juga berpendapat, bahwa prinsip 4R (reduce, reuse, recycle, replace) yang dilakukan setelah pemilahan sampah dapat menggurangi permasalahan lingkungan yang disebabkan oleh banyaknya sampah. Bahkan Muniyasamy dan Prasannan (2016) menambahkan upaya peningkatan jangka waktu suatu benda agar tidak mudah menjadi limbah (revitalization) pada hirarki pengolahan limbah padat.
Limbah B3 atau bahan berbahaya dan beracun membahayakan kesehatan manusia, makhluk hidup dan lingkungan apabila tidak ditangani dengan baik (Ratman dan Syafrudin, 2010). Sama halnya dengan IPAL, besarnya biaya pengolahan limbah B3 serta limbah cair dan juga anggapan bahwa jumlah limbah B3 serta limbah cair yang dihasilkan sedikit, maka hanya 7,69\% hotel melati di KPS yang mengolahnya. Pengolahan pada hotel tersebut pun umumnya hanya sampai pengumpulan limbah dan kemudian menyerahkan kepada pihak ketiga untuk penanganan lebih lanjut.

\section{KESIMPULAN}

Poin konservasi air melalui program Green Hotel di Kawasan Pariwisata Sanur belum diterapkan dengan baik oleh $76,92 \%$ hotel melati di kawasan tersebut, sedangkan sebanyak $23,08 \%$ hotel telah mengupayakannya dengan cukup baik.

Sehubungan dengan semakin meningkatnya isu air bersih di daerah Denpasar, maka diharapkan agar pengelola hotel melati mulai meningkatkan penerapan poin Green Hotel sebagai pedoman operasional hotelnya, khususnya pada poin konservasi air. Harapan kedepannya, hotel melati di Kawasan Pariwisata Sanur melalui program Green Hotel yang direkomendasikan oleh Kementrian Pariwisata Republik Indonesia, dapat memberikan dampak positif kepada masyarakat sekitar untuk menghadapi permasalahan krisis air dengan lebih baik.

\section{UCAPAN TERIMA KASIH}

Peneliti mengucapkan terima kasih kepada Tuhan YME. Ucapan yang sama peneliti sampaikan untuk dosen pembimbing atas bimbingan dan arahnya; orang tua yang telah memberi dukungan moral dan material; serta keluarga, teman-teman seperjuangan, dan seluruh kelompok masyarakat yang peduli terhadap permasalahan air di dunia, khususnya di Indonesia.

\section{DAFTAR PUSTAKA}

Anggita, D., Wardhani, A., dan Danusastro, Y. 2016. Penilaian Aspek Green Hotel 
Kelas Menengah (Hotel Bintang 1, 2, dan 3). Modul 16 (1): 21 - 28.

ASHRAE (American Society of Heating, Refrigerating and Air Conditioning Engineers). 2006. ASHRAE green guide:

The Design, Construction, and Operation of Sustainable Buildings. USA.

Bali Travel News. Aksi 500 Peserta "Beach Clean" di Pantai Mertasari Sanur. 18 November 2016.

Harmayani, K.D., dan. Konsukartha I.G.M 2007. Pencemaran Air Tanah Akibat Pembuangan Limbah Domestik di Lingkungan Kumuh (Studi Kasus Banjar Ubung Sari, Kelurahannn Ubung). Jurnal Permukiman Natah, 5 (2): 62108.

JICA (Japan International Coorperation Agency). 2006. The Comprehensive Study on Water Resources Development and Management in Bali Province in The Republic of Indonesia: Final Report: Supporting Report. Jepang.

Kementrian Pariwisata Republik Indonesia. 2016. Panduan dan Pedoman Pelaksanaan Green Hotel di Indonesia. Jakarta.

Kusminah, I.L. 2018. Penyuluhan 4R (Reduce, Reuse, Recycle, Replace) dan Kegunaan Bank Sampah Sebagai Langkah Menciptakan Lingkungan yang Bersih dan Ekonomis di Desa Mojowuku kabupaten Gresik. Jurnal Pengabdian Masyarakat LPPM Untag Surabaya, 3 (1): $22-28$.

Munisamy, M.K, and Prasannan, D. 2016. Implementation of $4 \mathrm{R}$ Techniques in Demolition Waste Management. International Journal on Applications in Civil and Environmental Engineering, 2 (5): 4 pages.
Ode, I. 2011. Intrusi Air Laut. Bimafika, 3: 266 $-271$.

Pemerintah Provinsi DKI Jakarta. 2012. "Vol. 5 Efisiensi Air (Panduan Pengguna Bangunan Gedung Hijau Jakarta Berdasarkan Peraturan Gubernur No 38/2012)". Jakarta: Pemerintah Provinsi DKI Jakarta.

Pramono, Jaya. 2016. Isu-isu Pengelolaan Lingkungan pada Hotel Berbintang di Bali. Jurnal Manajemen, Strategi Bisnis dan Kewirausahaan, 10 (1): 64 - 73

Ratman, C.R., dan Syafrudin. 2010. Penerapann Pengelolaan Limbah B3 di PT. Toyota Motor Manufacturing Indonesia. Presipitasi, 7 (2): 62 - 70.

Robinot, E. and Giannelloni, J. L. 2010. Do Hotels' Green Attributes Contribute to Customer Satisfaction? Journal of Services Marketing, Forthcoming. 33 Pages.

Subadra, I N. dan Nadra, N. M. 2006. Dampak Ekonomi, Sosial-Budaya dan Lingkungan Pengembangan Desa Wisata di Jatiluwih-Tabanan. Jurnal Manajemen Pariwisata, 5 (1): 46 - 64.

Tim Penyusun. 2018. Direktori 2018. Denpasar: Dinas Pariwisata Provinsi Bali.

UNWTO INSTO, 2017. Observatories: Sanur Tourism Observatory. http://insto.unwto.org/observatories/ (diakses pada 07.08.2018)

Wardi, I N. 2011. Pengelolaan Sampah Berbasis Sosial Budaya: Upaya Mengatasi Masalah Lingkungan di Bali. Jurnal Bumi Lestari, 11 (1): 167-177.

World Tourism Organization. 2018. UNWTO Annual Report 2017. UNWTO. Madrid.

Yudo, S. 2018. Upaya Penghematan Air Bersih di Gedung Perkantoran. Jurnal Teknologi Lingkungan, 19 (1): 97 - 106. 